\title{
ARTÉRIAS DOS ESTOMAGOS DE FETOS DE BOVINOS DA RAÇA NELORE
}

\author{
STOMACH ARTERIES IN NELORE BOVINES
}

\author{
Maria Angélica MIGLiNO': Joto Afonso Liberato DIDIO'
}

\begin{abstract}
RESUMO
Foi pesquisado o comportamento dos ramos arteriais destinados aos estomagos de felos de bovinos da raça Nelore. Foram utilizados 30 fetos, os quais tiveram suas artérias injetadas a partir da aona com látex Ncoprene e dissecadas. De axordo com as observaçoes realizadas, o rúmem recebia ramos arteriais (antérias ruminais) derivados da antéria esplênica, a qual supria lambém o retículo (artéria reticular) atravess de colateral originado a partir da artéria ruminal esquerda. O omaso recebia irrigaçào sanguínea a partir da artéria gástrica esquerda, a qual emitia um ou mais ramos para os sacos craniais do númem, e na curvatura do abomaso dava origem a artéria gastroepiplóca esquerda. As antérias gásuricas dircita c esquerda $\mathrm{c}$ as artérias gasurocpiploicas direita e esquerda anastomosavam-se entre si, respectivamente na pequena $\mathrm{e}$ grande curvaturas do abomaso.
\end{abstract}

UNITERMOS: Anatomia, bovinos; Estômago, artérias; Vascularizaçăo

\section{INTRODUÇÃO}

Esta pesquisa anatômica visou obtcr subsídios sobre a irrigaçăo dos estômagos de ruminantes domésticos, mais propriamente dos bovinos da raça Nclore, os quais constitucm hoje o major contingente do rebanho de animais destinados à produçăo de came no Brasil.

Com o objetivo de estudar a ramificaçăo dos principais troncos derivados da aorta (tracto abdominal), investigamos também a distribuiçấo de cada anceria que se dirige à parede dos estômagos (nimen, retículo, omaso e abomaso) destes animais, analisando seus territórios de vascularizaça e suas anastomoses.

De posse destes achados, acredilamos que a pesquisa poderá servir como base informativa à Cirurgia Veterinária c a cstudos de Anatomia Comparativa.

Na literatura pertinente ao assunto, encontramos alguns trabathos os quais tiveram por objetivo estudar a origem e a distribuiçá dos ramos colaterais da aorta que se destinavan às vísceras abdominais, inclusive aos estômagos. Nenhum delcs, entretanto, continha a ramificaçăo de tais artérias nos estômagos dos bovinos da raça Nelore.

Assim, as referências que encontramos sto, na maioria, pertinentes aos bovinos de origem europcia, sendo que apenas PEDUTI NETO e PRADA '“ (1970); GODINHO et al.' (1981); ARAÚJO' (1982) apresentaram dados referentes aos bovinos de origem indiana.

\section{MATERIAL E MÉTODO}

Este trabalho foi realizado no Departamento de Cirurgia da Faculdade de Medicina Veterinária e Zootecnia da Universi- dade de Săo Paulo e o matcrial necessário foi obudo $\mathrm{em}$ dois grandes Frigoríficos do interior de Sao Paulo - Frigocstc de Săo José do Rio Preto e Frigorífico Taquaritingat de Taquaritinga - SP.

Utilizamos 30 fetos de bovinos da raça Nelore (machos e remeas), retirados de vacas abatidas em diferentes estágios de gestaçào.

Nos Frigoríficos, após a identificaçåo das mâes, permanecíamos na linha de matança, coletando cada útero gestante, os quais, momentus apkós, cram incisados para que deles retirássemos os fecos. Estcs cram trazidos a laboratorio para a injeçao dos vasos c a lixação das peças.

No processo de injecăo, isolávamos a aorta no seu tracto prédiafragmático, mediante abertura da cavidade torácica e colocaçåo de cânula apropriada no interior do cilado vaso. Uuilizávamos látex Neoprene 650 corado para o preenchimento das artérias sob pressăo constante.

Após cste procedimento, as preparaçoes eram fixadas em soluçâo aquosa de formol a $10 \%$.

Iniciamos a dissecçăo, abrindo a cavidade abdominal mediante incisa das paredes e rebaumento do diafragma. Após a identificaçăo das artérias celiaca e mesentérica cranial segulamos o trajeto de seus ramos arteriais até atingir sua terminaçăo nas paredes dos estốmagos.

De cada preparaça foram feitas fotografias e esquemas, os quais serviram de base para a ilusuraça dos resultados.

Classificamos os vasos adotando terminologia que facilitasse a descriçầo da circulaçăo sanguínea arterial completando, assim, a nomenclatura existente.

\footnotetext{
- Pesuisa financiada pelo CNPq

1-Professor Associado-Faculdade de Medicina Vecerinhina e Zocuecnia da USP

2-Professor Visitante-Eacola Pauliata de Medicina, Sso Paulo, Brasil
} 


\section{RESULTADOS}

A artéria celíaca originava-se isoladamente da aorta abdominal em 28 casos sobre $30(93,3 \% \pm 4,5)$, ramificando-se na parede dos estômagos, irrigando o baço e o fígado.

Em apenas 2 casos $(6.6 \% \pm 4,5)$, correspondentes a 2 machos, a referida artéria originava-se de um tronco comum a ela e a artéria mesentérica cranial (tronco celíaco-mesentérico), destinando-se, apos abandonar o mencionado tronco, as mesmas visceras abdominais.

A artéria celíaca em 26 casos (12 remeas e 14 machos), ou seja, $86,6 \% \pm 6,2$, dividia-se em um tronco grastrolicnal, comum às artérias lienal e gástrica esquerda, e em uma artéria hepácica

As 4 preparaçסes restantes mostraram outros arranjos de distribuiçăo anerial ou seja, em 3 machos $(10 \% \pm 5,5)$ verificamos disposiçæo urifurcada das artérias esplênica, gástrica esquerda e hepática e em uma fêmea $(3,3 \% \pm 3,3)$ observamos a trifurcaça da aruéria celfaca $\mathrm{cm}$ artéria esplênica, artéria ruminal esquerda e artéria hepática.

A artéria esplênica supria em todos os casos o rúmcn c o relículo. Logo após sua origem ela irrigava o baço auravés de um ramo $(33,3 \% \pm 8,6$ - correspondentes a 5 machos c 5 remeas) ou dois ramos $(13,3 \% \pm 6,2$ - correspondentes a 3 machos e 1 femea). No primeiro caso, este ramo se bifurcava antes de atingir o parênquima do baço e no scgundo caso um dos ramos apresentava bifurcaçăo no hilo esplênico.

Em ambas as oportunidades $(46,6 \% \pm 9,1)$, a artéria esplēnica fornecia urn tronco comum as artérias ruminais dircita e esquerda.

A artéria ruminal direita percorria sempre o sulco longitudinal direilo, alcançava o sulco caudal do rúmen $\mathrm{c}$ os sulcos coronários, ramificando-se nas artérias corunárias dorïils c ventrais dos sacos ruminais.

A artéria ruminal esquerda contornava sempre o sulco cranial do númen, atingia o sulco longitudinal esquerdo e ramificava-se à semelhança da artéria ruminal dircila. Antes, porém, de alingir o sulco longitudinal esquerdo ela originava a artéria reticular.

A artéria esplênica originava-se $\mathrm{cm}$ tronco comum com a artéria ruminal direita em 9 casos dos 30 examinados ( $30 \% \pm$ 8,4 - correspondentes a 7 machos e 2 femeas) fornecendo um ramo colateral a artéria ruminal esquerda.

Em 4 das 30 peças examinadas $(13,3 \% \pm 6,2$ - correspondenles a 3 fêmeas e 1 macho) a artéria esplênica ruminal direita e artéria ruminal esquerda resolviam-se por trifurcaçăo.

A artéria esplênica originava-se $\mathrm{em}$ tronco comum com a antéria ruminal esquerda em 3 das 30 preparaçóes (10\% $\pm 5,5$ - correspondentes a 2 machos e 1 femea), enquanto que a artéria ruminal direita saía isolada à jusante do cilado tronco.

A artéria hepática dividia-se em todas as dissecaçoes em um ramo direito e un ramo esquerdo. $O$ ramo direito era sempre curto e destinava-se ao lobo direito e ao lobo caudado do fígado, emitindo durante o seu trajeto a artéria cística. O ramo esquerdo cra longo e bifurcava-se $\mathrm{cm}$ artéria gásurica dircila o artéria gastroducolenal. A artêria gástrica dircila alıngè o omento menor e a curvatura menor do abomaso onde wo anastomosava com artéria gástrica esquerda. A artéria gasuroduodenal alcançava o duoxkno e dava origem à artéria gastroepiplóica direita que se anastomosava na curvatura maur do abomaso com a anéria gastrocpiplóica esquerda.

A artéria gásurica esquerda emitia, nos 30 casos estudados. um ou mais ramos para a parede os casos craniais do rúmen. c caminhava em dircça ao omaso, atravessando uxdo óryajo. continuando-se na menor curvalura do abomaso ale anastomosar-se com antéria gástrica direita. Antes, porém, de atingir o abomaso, oferecia sempre um ramo colateral destnado à curvatura maior do abonasio, a denominada artéria gastrocpiplóica esquerda, que por sual ve\% si: analstomosiava com a artéria gastroepiplóica dircila. Ambas origunavam ramos perpendiculares a seus urajetos dirigidos au abomaso.

\section{COMENTÁRIOS}

Embora vários tratadistas facam relatos sobre os ramos da artéria celiaca, estas informaçócs, na maioria das vezes, săo genéricas quando disem respeito a ruminantes (BOSSF, s.d.; MONTANÉ; BOURDFILE'14, 1917; GONZALEZ $Y$ GARCIA; GONZALEZ ALVAREZ", 1929; ZIMMERL el al. ${ }^{20}$, 1930; FAVILLI*, 1931; ELI.EMBERGER; BAUM'. 1932; MARTIN; SCHAUDER ${ }^{3}$. 1935; DUBERSTEIN; HOFFMANN4, 1964; SCHWARZE; SCHRODER ${ }^{17}$, 1972) : quando tratam particularmente de bovinos (SISSON: GROSSMANN", 1959; KOCH'. 1965 e GETIY', 1981). provavelmente, considerando aqueles animais de origem europeia. Apenas o trabalho de PEDUTT NETO e PRADA * (1970) sobre a origem da artéria celíaca c artéria mesentérica cranial e a tese de ARAÚJO' (1982) sobre a ramificação da arteria celíaca nos bovinos azebuados possuem dados relati. vos aos Bos indicus.

Nossos resultados confimam os dos aulores precedentes no que diz respeito à artéria celíaca e seus ramos que irrigam os cstômagos, o baço. parte do pâncreas e o fígado. Entrelanto, as variaçoes yue ocorrem nas descriçðes, desde sua urigem, sâ dignas de nota, especialmente em alguns casos, quando elas podem aparcecer em tronco comum com a artéria mesentérica cranial, formando um tronco celíaco-mesentérico encontrado por SIEBER “ $(1403) \mathrm{em}$ apenas 2 preparacoes, por GODINHO et al'. (1981) frequicntemente e por nós em 6,6\%.

Relativamente à divisăo c ramificaça da artéria celíaca, verificamos que a inexistência do tripus celiacus é uma caracierística dos ruminantes, muito embora de acordo com nossos resultados esta disposiçăo ocorra em apenas $10 \%( \pm 5,5)$ do nosso matcrial.

Entre os autores que descrevem urifurcaçăo da artéria celíaca cncontra-se FAVILLI ${ }^{\circ}$ (1931) que a encontrou nos artiodáctilos. Relata que a aréria celfaca destes artiodáculos divide-se em 3 ramos, porém eles sło denominados artéria ruminal direita. artéria ruminal esquerda e artéria hepática. 
A divis:o por trifurcacto, que encontramos em 3 dos animais que examinamos, te tamberm considerada por NICKEL et al. ${ }^{\text {is }}$ (1981). Entretanto, para eles, a artéria ruminal esquerda podc frequentemente ter origem neste ponto de trifurcaçăo, ou mesmo mais raramente a anćria ruminal direita.

Também ARAÚJO' (1982) considera a antéria celfaca dividindo-se em 3 ramos especificados, porém estes 3 ramos como antéria esplênica, tronco inominado c artéria gástrica em 505 das peças examinadas por ele; ou mesmo aréria ruminal direita, tronco inominado e artéria gástrica csquerda em $6.7 \%$ das preparaçoes; c ainda artéria ruminal direita, tronco inominado e artéria esplênica $(6,7 \%)$, e em rara oportunidade $(3,3 \%)$ artéria hepática, tronco inominado e artéria esplênica.

Levando-se em conta os resultados que obtivemos para os bovinos da raça Nelore, podemos supor que o tronco inominado considerado por ARAÚJO' (1982) poderia ser referido como aréria gástrica esquerda, especialmente em vista dos resultados obtidos em 3 das nossas 30 preparaçoes que mostraram disposiçăo trifurcada (anéria esplênica, anéria hepática e artéria gástrica esquerda). Entretanto, na maioria dos casos que examinamos $(86,6 \%)$, verificamos a bifurcaça da artéria cellaca em tronco grastrolienal comum às antérias lienal e gástrica esquerda e artéria hepática. Vale dizer que a disposiço por bifurcacto também e assinalada na tese de ARAÚJO' (1982), porém, em artéria esplénica e tronco inominado (13,3\%); artéra gásurica esquerda e tronco inominado $(10,0 \%)$; e arteria esplenica e ruminal direita (3,3\%).

Para SIEBER"(1903), no bovino adulto, as anérias ruminal e recicular apresentam-se como vasos dominantes independenles devido ao seu camanho e disposiçăo, como por exemplo a arteria ruminal direita que parece o vaso principal do qual parte a antéria lienal. Nos animais jovens, os 3 vasos tanto pelos seus calibres quanto pelos seus ångulos de ramificaçăo parecem pequenos ramos secundários da aréria lienal, gásưica esquerda e mais raramente da artéria hepática.

Os demais autores (ELLEMBERGER: BAUM', 1932) afirmam que a artéria celiaca fornece 6 ramos (artéria frênica, arteria ruminal direita, artéria ruminal esquerda, artéria esplênica, artéria gástrica e antéria hepática); 5 ramos (artéria ruminal direita, artéria ruminal esquerda, artéria esplênica, artéria gástrica esquerda e artéria hepática) - MARTIN'12 (1912); DOBBERSTEIN; HOFFMANN * (1964) e SCHWARZE; SCHRODER' (1972); antéria frênica caudal, ramos suprarenais craniais, artéria lienal, antéria hepática e artéria gástrica esquerda. GODINHO el al." (1981) mencionam 8 ramos (anteria frênica, anteria esplénica, antéria hepática, além de 5 ramos gástricos, um destinado ao folhoso e outro a coagulador e mais as artérias ruminais direita e esquerda e artéria reticular)-LESBRE"'(1923).

Embora MONTANE; BOURDELLE'14 (1917) cilem 6 vasos, eles næo incluem, a semelhança de ZIMMERL et al ${ }^{20}$ (1930) e ELLEMBERGER; BAUM' (1932), a artéria gástrica esquerda, mas sim a arteria reticular, do mesmo modo pelo qual BRUNI; ZIMMERL' (1947) omitem anteria esplênica e acrescentam a artéria frênica no grupo das 6 .

Ja BOSSP (s.d.); MARTIN; SCHAUDER ${ }^{13}$ (1935) limitam-sc a especificar 4 ramos derivados da artéria celíaca sendo que BOSSI (s.d.) descreve as antérias frênica, esplênica. gástrica esquerda c hepática, e MARTIN; SCHAUDER ${ }^{13}$ (1935), as arérias ruminais direita e esquerda, a antéria gástrica esquerda e a artéria hepática. Para ARAÚJO' (1982) estes quatro vasos foram denominados antéria esplênica, antéria gástrica esquerda, anéria hepática e uronco inominado.

Analisando agora cada ramo derivado da anéria celíaca, verificamos que a artéria esplênica considerada por SIEBER' (1903) como parte integrante de um tronco visceral comum com a anteria ruminal direita, ou com a anéria ventricular destina-se a nutrir o baço e rúmen percorrendo seus sulcos ruminais. A anćria ruminal direita, na opiniz̄o de SIEBER ${ }^{\text {เ }}$ (1903), oferece ramos que se dispoem na superficie dorsal direita do númen e se anastomosam com ramos da antéria reticular, ou percorrem a superfícic ventral direita do rúmen $\mathrm{c}$ se anasiomosam com ramo da arćria ruminal esquerda. Dela partem também ramos epiplóicos, antéria coronária dorșal direita, antéria coronária dorsal esquerda, antéria coronária ventral csquerda e um ramo longitudinal que é na descriça do autor o final da antéria ruminal direita. A artéria ruminal esquerda geralmente inicia-se num tronco comum com a anckria reticular, a qual irriga também o esoffago.

Os resultados dos trabalhos de SIEBER" (1903) nos informam ainda que a antéria lienal, que eventualmente inicid-se separadamente na artéria cólica, lança ramos que nutrem o terço dorsal do baço antes de penetrar no órgāo, e que, ao contrário dos outros animais, a anéria lienal nåo sai mais do baço.

Para GODINHO et al." (1981) e NICKEL et al. 1s (1981), a ar téria lienal emerge sempre da artéria celíaca, emitindo, nu opiniâo dos primeiros autores, ramos pancreáticos, além đo) seu território de distribuiçàn (rúmen e baço) para o qual os autores são unånimes em concordar com os achados de SIEBER 10 (1903), exceto quanto à origem da artéria reticular, a qual pode ter origem na artéria gástrica ou na próprì artéria esplênica nos pequenos ruminantes (NICKEL et al.". 1981).

Nossas dissecaçoes mostraram em 9 casos (30\%) resultados semelhantes aos de SIEBER" (1903) quando a direita, oferecendo um ramo colateral à artéria ruminal esquerda.

Porém, nos bovinos da raça Nelore a anceria esplennica e as anérias ruminais direita e esquerda podem apresentar divisăo por trifurcaço $(13,3 \%)$, ou mesmo a artéria esplénica pode surgir juntamente com a artéria ruminal esquerda $(10,0 \%)$, porém nunca com a aréria cólica como supos SIEBER" (1903). ou mesmo com tronco inominado $(16,7 \%)$ como descreveu ARAÚJO' (1982).

Este tronco inominado surge como um doe ramos terminais da artéria celfaca $\mathrm{em} 96,7 \%$ das peças observadas pelo auwor e a antéria numinal direita é vista como colateral da antéria esplénica (70\%), como ramo terminal da antéria celíaca $(16,7 \%)$ e como colateral ou do tronco inominado (10\%) ou da aréria celfaca $(3,3 \%)$ nos bovinos azebuados.

Já a antéria gástrica esquerda, considerada continuaçlo da artéria celíaca por SIEBER" (1903), exceto nos caprinos onde 
ela se origina na aréria hepática NICKEL et al. ${ }^{5}$ (1981), penetra entre o rúmen e o retículo, depois entre o omaso e o abomaso, insinuando-se e enviando ramos na incisura rumino-reticular ao retículo e ao omaso, além de dar origem à artéria gástrica esquerda e à artéria gastroepiplóica esquerda. Estas acompanham a pequena e grande curvatura da abomaso e $x$ anastomosam com as antérias gástrica direita e gastroepiplóca direita derivadas da artéria hepática como afimam SIEBER" (1903); GODINHO et al." (1981); NICKEL et al..$^{\text {'s }}$ (1981), e também, de acordo com os nossos resultados.

Finalmente, a artéria hepática, considerada por lodos os autores como ramo isolado da artéria celíaca, ramifica-se enviando colaterais para o pâncreas, lobos hepáticos, vesícula biliar. Além disso, dá origem às antérias gástrica dircita c gastroduodenal direita; vasos se dirigem às paredes do abomaso anastomosando-se com as artérias gástrica esquerda e gastroepiploica esquerda.

\section{CONCLUSŌES}

Do que acabamos de expor, podemos concluir que:

1. Nos bovinos da raça Nelore, a antéria celíaca originou-se, isoladamente, da aorta abdominal em 93,3\% dos casos estudados e originou-se em tronco comum com a artéria mesentérica cranial nas preparaçðes restantes $(6,6 \%)$, ramificando-se em lodos os casos nas paredes dos estômagos, baço c figado destes ruminantes.

2. Nossas dissecaçoes $(86,6 \%)$ mostraram que a artéria celíaca se dividia num tronco gastrolienal comum às artérias lienal gástrica esquerda e numa antéria hepática.

3. Em $10 \%$ das pecas examinadas, verificou-se que a ancria cellaca trifurcava-se em antéria esplénica, ancéria hefútica c antéria gástrica esquerta, ou em rara oportunidade $(3,3 \%) \mathrm{cm}$ antéria esplénica, anteria numinal esquerda e ancéria hepáticia

4. A antéria esplênica supria em todos os casos o rúmen e o retículo, oferecendo ramo para o baço, e as artérias ruminais direita e esquerda, sendo que desta última se originava a ankéria recicular.

5. A ancria numinal direila percorria o sukco bongitudinal direito do rímen, alcançava o sulco caudal e os sulcos coronários, e fornocia as artérias cononárias dorsais e ventrais do rúmen.

6. A artéria ruminal esquerda contornava o sulco cranial do rumen e atingia o sulco longitudinal esquerdo.

7. Em $30 \%$ das dissecaçoes a artéria esplênica originava-se em tronco comum com a artéria ruminal dircila e em 13.3\% dos casos a antéria esplênica, a arćria ruminal direit e a artcria ruminal esquerda resolviam-se por trifurcaça. Em apenas 3 oportunidades (40\%) a arcéria esplenica originava-se em tronco comum com a artéria ruminal esquerda.

8. A antria hepática dividia-se em lodas as dissecaçðes em um ramo direito e um ramo esquerdo. $O$ ramo direito destinava-se aos lobos direito e caudado do fígado, emitindo durante o seu trajeto artéria cística. O ramo esquerdo, longo. bifurcava-se numa aréria gástrica e numa artéria gastroduodenal, da qual emergia a artéria gastrocpiploica dircita.

9. A artéria gástrica esquerda emitia sempre um ou mais ramos para a parede dos sacos craniais do rúmen e percorria a superfície do omaso, continuando-se na menor curvalura do abomaso e dava origem a artéria gastrocpiplóica esquerda.

10. As arı́rias gástricas dircita e esquerda e as artérias gastroepiplóicas dircila e esquerda anastomosavam-se entre si respectivamente na pequena e grande curvaturas do abomaso.

\section{SUMMARY}

The distribution of the arteries in the gastric chambers of 30 fetuses of Nelore bovines was studied, after the injection of Neoprene latex. The latex was injected through the aorla, the specimens were then fixed with 10\% formaldehyde solution and dissected. The rumen was supplied by branches (ruminal aa.) given off by the splenic a. the latter supplied also the reticulum (reticular a.) by means of a collateral originated from the left ruminal a. The omasum was supplied by the lefi gastric a., wich provided one or more branches to the cranial sacs of the rumen and, in addition, in the curvature of the abomasum, originated the left gastro-omental a. Anastomoses were found between the right and left gastric as. and the right and left gastro-omental aa. in the lesser and greater curvature of the abomasum.

UNITERMS: Anatomy of catue; Stomach, artery; Vascularization

\section{REFERÉNCIAS BIBLIOGRÁFICAS}

01 -ARAÚJ(), J.C. Contribuiçāo ao estudo dos ramos da artéria celliaca em fetus de bovinos azebuados. Slo Paulo, 1982. Dissertaçà (Mestrado) - Faculdade de Medicina Veteriníria e Zoolecnia. Universidade de S\$o Paulo.

02-BOSSI. V. Angiologia. In: BOSSI, V.; CARADONNA, G.B.; SPAMPANI, G.; VARALDI, L.; ZIMMERL, U. Trattoto di anatomla veterinaria. Mileno, Francesco Vallardi, s.d. v.2, p. 205-6. 210.

03-BRUNI, A.C.; ZIMMERL U. Anatomia degll animall domesticl. 2. od. Milano. Francesco Vollardi, 1947. v.2. p.350-1.

04-DOBBERSTEIN, J.; HOFFMANN, G. Lebrbucb der vergleichenden Anatomle der Haustlere. Leipzig. S. Hirzel. 1964. v.3. p.50.

05-ELLEMBERGER, W.; BAUM, H. Handbuch der verglekchenden Anatomle der Hautiere. 17. Auf. Berlin. Julius Springer, 1932. p. 705-7.

06-FA VILLI, N. Nozionl comparate dl anatomia a fislologla deg॥l an Imall rurall. Torino. Unione Tipografico-Editrice Torinese, 1931. p. 403.

07-GETTY, R. ed. Sisson/Grossman anatomia dos animais 
domestican. 5. ed. Rio de Jeneiro, Interamericana, 1981. v. 1. p. $921-2$.

08-GODINHO, H.P.; CARDOSO, F.M.; NASCIMENTO, J.F. Anatomla dos ruminantes dométicos. Belo Horizonte, 1981. p. $372-4$.

09-GONZALEZ y GARCIA, J.; GONZALES ALVAREZ, R. Anatomla comparada de los animales domesticos. 3. ed. Zaragoza, Tip. 1" Academica, 1929. p. 634.

10-KOCH, T. Lehrbuch der veterinär-anatomle. Jena, Gustav Fischer. 1965. v. 3. p. 120-4.

11-LESBRE, F.X. Precls d'anatomle comparée des animaux domestiques. Paris, J.B. Baillière, 1923.

12-MARTIN, P. Lehrbuch der Anatomle der Huustiere. Siutigart, Schickhardt \& Ebner, 1912. v. 1. p. 548.

13-MARTIN, P.; SCHAUDER, W. Lehrbuch der Anatomle der Haustiere. Stuttgart, Sckhardı \& Ebner, 1935. v. 3. p. 227-9.

14-MONTANE, L.; BOURDELLE, E. Anatomie régionale des animaux domestlques. Paris, J.B. Baillière, 1917. v. 2. p. 275.
1S-NICKEL, R.; SCHUMMER, A.; SEIFERLE, E. Anatomy of the domestke anlmake Berlin, Verles Paul Parey, 1981, v.3, p. 260-5: The circulatory system, the akin and the culanoous organs.

16-PEDUTI NETO, J.; PRADA, I.L.S. Origem das artérias celíaca e mesentérica cranial, por tronco comum, em fetos de bovinos azebuados. Rev.Fac.Med.Vet.Zootec.Unlv.S.Pauk, v. 8, p. 399-402, 1970.

17.SCHWARZE, E.; SCHRODER, L. Compendio de anatomin veterináriu. Zaragoza, Acribia, 1972. v. 3. p. 71.

18-SIEBER, H. F. Zur vergleichenden anatomle der Arterien der Bauch-und Beckenhole bel den Haussauge, 1903. (Inaugural Dissertation) - Tier

19-SISSON, S.; GROSSMAN, J.D. Anatomla de los anlmules domestkos. 4. ed. Barcelona, Salvat. 1959. p. 705-6.

20-ZIMMERL, U.; BRUNI, A.C.; CARADONNA. G.B.; MANNU, A.; PREZJUSO, L. Trattato dl anatomla veterínárle. Milano, Francesco Vallardi, 1930. v. 2, p. 163-4, 167.

Recebido para publicacio em 09/04/92 Aprovado para publicaçăo em 11/12/92 


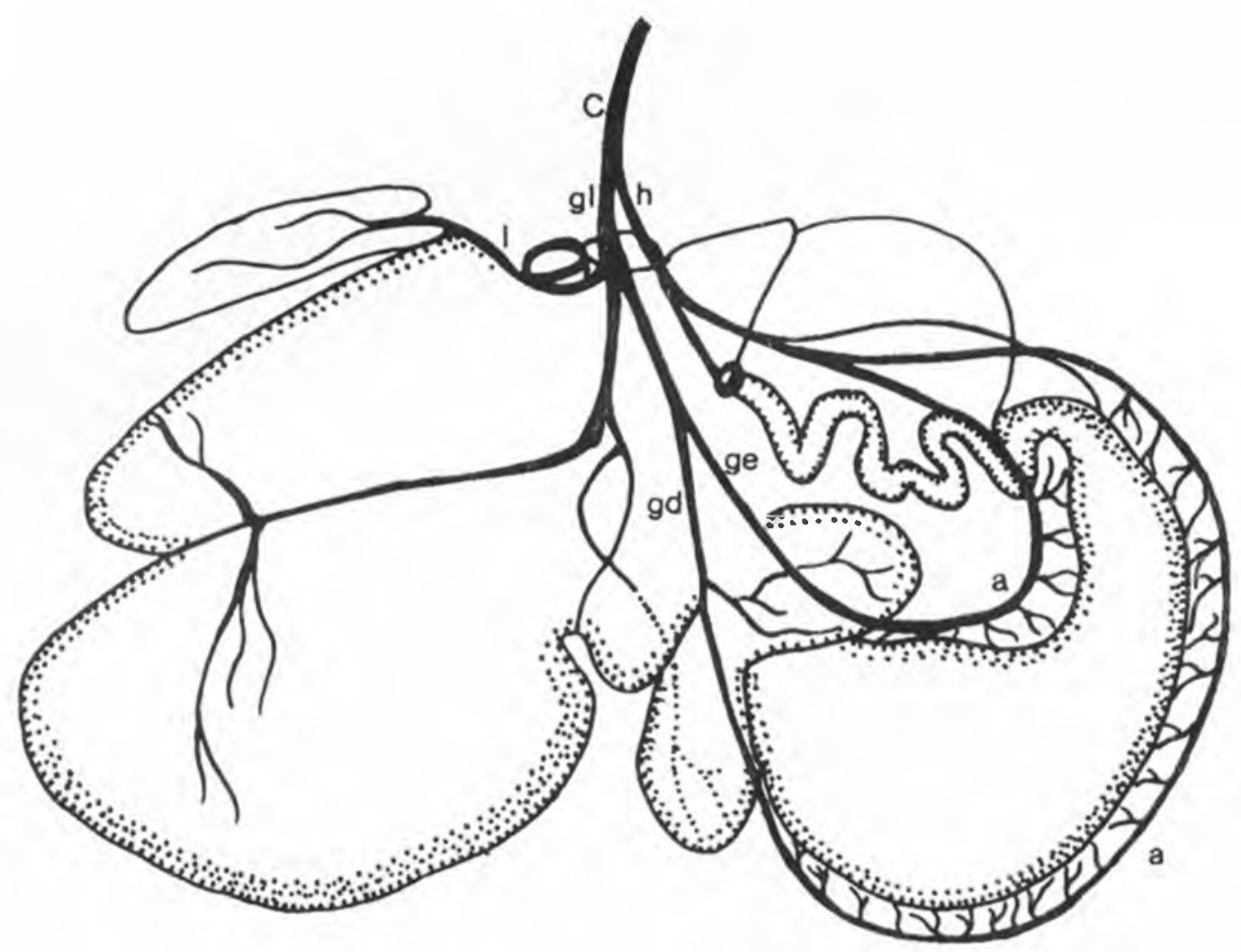

FIGURA 1

esquema da disposiçāo das artérias do estômago de um bovino fềnea, da rą̧a Nelore. Da artéria celíaca (c) emergem um tronco gastrolienal (gl) e uma artéria hepática (h). A antria lienal (l) supre o númen e o retículo $\mathrm{co} \mathrm{baço.} \mathrm{As} \mathrm{antérias} \mathrm{gástricas} \mathrm{esquerda} \mathrm{(ge),} \mathrm{dircita} \mathrm{(gd)} \mathrm{e} \mathrm{hepática} \mathrm{irrigam} \mathrm{pane} \mathrm{do} \mathrm{rúmen,} \mathrm{omaso} \mathrm{c}$ obomaso, scndo que se verifica entre scus ramos anastomoses $(\mathbf{a})$. 